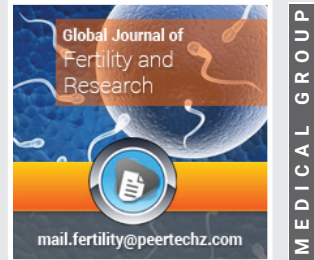

\section{Description of the}

\section{characteristics influencing} the therapeutic management of infertile couples in western

\section{Algeria}

\author{
Belhachemi N*, Zelmat SA, Chafi B, Foughal M and \\ Mohand Arabe W \\ Medical School Ahmed Benbella 1 Oran, Head of Unit in Medically Assisted Procreation, Obstetric \\ Gynecology Service Hospital and University, Oran, Algeria
}

Received: 07 November, 2020

Accepted: 15 December, 2020

Published: 16 December, 2020

*Corresponding author: Belhachemi N, Medical School Ahmed Benbella 1 Oran, Head of Unit in Medically Assisted Procreation, Obstetric Gynecology Service Hospital and University, Oran, Algeria, Tel: 0798296672; E-mail: inesse06@hotmail.com

Keywords: Infertile couple; Type and Duration of infertility; Age of woman; Age of man; Origin and cause of infertility

https://www.peertechz.com

\section{Check for updates}

\title{
Summary
}

Objective: The aim of this work is to describe and identify the characteristics that can influence the care of these infertile couples.

Material and method: This is a prospective, monocentric study, extending over a period of four years. It is descriptive of a sample of 760 infertile couples treated in the gynaecology and obstetrics department of the Oran hospital and university establishment of 1st November 1954.

Results: The study revealed that primary infertility was $74 \%$. The average duration of infertility was $4.8 \pm 0.2$ years (minimum 6 months, maximum 25 years); the average age of infertile couples was $33.2 \pm 0.4$ years (minimum 18 years, maximum 45 years) in women and $39.5 \pm 0.5$ years (minimum 23 years, maximum 71 years) in men. The male origin of infertility was $30.4 \%$, mixed at $29.2 \%$, female at $27 \%$ and unexplained at $13.4 \%$. Oligo-astheno-severe teratospermia dominated male infertility at $30.4 \%$. Tubal causes $23.4 \%$ and ovulatory causes $22.8 \%$ were mainly of female origin of infertility.

Conclusion: The study of these characteristics showed a delay in the treatment of infertile couples. The primary type and long duration of infertility and the advanced age of both women and men make the chances of conception minimal. The male origin of infertility is more important than the female origin, suggesting a deterioration in sperm parameters. Tubal causes in the female origin of infertility are important because of the increasing prevalence of sexually transmitted infections.

\section{Introduction}

Infertility is characterised by a couple's inability to conceive a child. It is defined by the World Health Organization (WHO) in 2009 [1] as the failure to achieve a clinical pregnancy after 12 months of unprotected sexual intercourse and after six months [2] if the woman is over 35 years of age. Infertility is said to be "primary" if the couple has never conceived,and it is said to be "secondary" if a pregnancy has occurred $[3,4]$ in the past. According to the WHO, 10 to $15 \%$ couples in the world are concerned [5], which corresponds to more than 186 million people worldwide, the majority of whom are from the developing countries [6]. Africa counts about 20 - 35 million, particularly higher in Sub-Saharan Africa [7]. In Canada, 11$16 \%$ of couples are estimated to be affected [8]. In France, one in seven couples are infertile and one in ten are undergoing treatment [9]. In Tunisia, 15\% of couples of childbearing age [10]. In Algeria, despite population growth, the Ministry of Health estimates this rate at $10.6 \%$ [11].

Faced with a couple who decide to consult for infertility, the gynaecologist has to identify the various social, psychological, medical and sexological elements. He also has the task of investigating the factors that influence infertility, which are represented by: the primary or secondary type of infertility, the 
duration of infertility, the age of the woman and the age of the man, and the origin or cause of the infertility.

Some studies $[12,13]$ have shown that primary infertility reduces the chances of pregnancy compared to secondary infertility.

As the duration of infertility increases, the chances of pregnancy decrease. In fact, $80 \%$ of pregnancies are obtained in the first six cycles of pregnancy. $55 \%$ of those who remain so-called hypofertile will achieve a pregnancy in 36 months and after 2 years, $5 \%$ of couples are said to be infertile with an almost zero rate of spontaneous pregnancy [14].

A woman's age is a determining factor in fertility. Fertility in women declines with increasing age, with a sharp increase in fertility decline from the age of 35 onwards [15]. For men, sperm changes are not noticeable until the age of $45[16]$; however, the foetal risk of genetic diseases such as Down's syndrome, when the father's age exceeds 45, is recognised [16].

Infertility is no longer a woman's prerogative, as is the case in our society, where she is considered to be the primary cause of the problem. The epidemiological investigation by Thonneau, et al. in 1991 highlighted the shared responsibility of men and women for the couple's infertility [9]. Infertility in men quickly emerged as an important factor, accounting for $50 \%$ of the causes of difficulties in conceiving [17]. The study by Agarwal, et al. showed that male infertility rates were higher in Africa and Central and Eastern Europe, compared to North America and Australia [18]; It has been observed that a high proportion of young men currently have unfavourable sperm characteristics [19], with damaged mucus-sperm histocounts [20].

The identification of these characteristics makes it possible to establish a prognosis and consequently influence therapeutic management.

The aim of this work was to describe and identify the characteristics which influence the management of these infertile couples.

\section{Material and method}

\section{Type of study}

This is a prospective and descriptive study of a sample of infertile couples cared for in the gynaecology and obstetrics department of the Oran hospital and university establishment.

It is a monocentric study over a period of 4 years, from 1 January 2009 to 31 December 2012.

\section{Study population}

This is a population of infertile couples who have consulted for the first time in the fertility unit of the obstetric gynaecology department. The recruitment of couples was done in an exhaustive manner.

\section{Criteria for inclusion}

We included in the study:

- infertile couples residing in western Algeria.

- infertile couples whose man and woman were jointly involved in the care within the unit.

- couples whose wife was 45 years old or less.

\section{Exclusion criteria}

- couples who refused to do their follow-up jointly within the unit

Thus our study sample was reduced to 760 instead of 972 couples.

\section{Data collection}

The survey was carried out by means of a questionnaire which consisted of four parts:

- The first part allows the identification of the infertile couple, age of the woman, man and socio-economic level.

- The second part specifies the history, type and duration of infertility.

- The third section deals with the origin of the infertility (female, male, mixed or unexplained) and allows the identification of the possible cause(s) of basic infertility by means of a check-up.

This assessment includes:

- in men: a spermogram and a spermocytogram,

- in women:

$>$ a hormone test:

- Prolactin and TSH us

- FSH, LH, oestradiol performed on the 2nd-3rd day of the cycle.

- and progesterone made on the 23rd day of the cycle.

$>$ Endovaginal ultrasound (at the beginning of the cycle). A follicular monitoring of j10-j14) and hysterosalpingography.

- in the couple: a post-coital test was carried out despite all the discussions on this subject.

Informed and signed consent was obtained from the couple.

\section{Factors studied}

General factors

- Socio-economic level 
We grouped them into three levels: the high level group : couples with a high income and a high intellectual level. The medium level includes a working member of the couple and a medium intellectual level. The low level represents the couple with a low income and no level of education.

- Type of infertility: is classified as primary or secondary.

- Duration of infertility is assessed according to its duration (years): $\leq 2,3-5,>5$.

After 2 years, the chances of spontaneous conception become nil. Each additional year constitutes a pejorative element.

- The age of the woman is divided into classes: $\leq 30,30-35$, 36-40, 41-45

- The age of the man is also divided into classes: $\leq 30,30-$ $35,36-40,41-45,>45$ years old.

At the age of 35 years for women and 45 years for men are taken as a benchmark for a clear decline in fertility.

The origin of infertility is classified as female, male, mixed or unexplained.

- The female origin of infertility is divided into ovulatory, tubal, endometriosis, uterine and cervical causes.

- The masculine origin is divided according to the anomalies of the spermogram interpreted according to the WHO 2010 standards and for morphology, the classification used was David's classification:

- The spermogram is considered normal if the count is $\geq 15$ million spermatozoa per ml, motility $\mathrm{a}+\mathrm{b}>30 \%$ and typical shape $\geq 30 \%$.

- Asthenospermia corresponds to $(\mathrm{a}+\mathrm{b}<30 \%)$,

- Teratospermia is when the typical form $<15 \%$.

- Moderate oligo-astheno-teratospermia (OAT): the count is $5-15$ millions/ ml, mobility $10<\mathrm{a}+\mathrm{b}<30 \%$ and the typical form at least $15 \%$.

- Severe OAT: the count is $<5$ million/ml, mobility $\mathrm{a}+\mathrm{b}<$ $10 \%$ and the typical form less than $10 \%$.

\section{Statistical analysis}

The statistical analysis of the data was carried out using EPI Data 3.1 software.

The estimation was made by frequency for qualitative variables and average for quantitative variables.

\section{Results}

\section{Causes of exclusion}

- Of the 972 infertile couples recruited, only 760 (78\%) infertile couples constituted the sample to be studied. $22 \%$ of the couples were disqualified, the main causes being: $10.7 \%$ of the couples never came back to the unit, $4.8 \%$ the woman was over 45 years of age and $6.5 \%$ the spouse refused to have a spermogram (Figure 1).

\section{Study of the characteristics influencing the infertility of couples}

A. General factors: Table 1

- $71 \%$ of the couples had a medium socio-economic level and $14 \%$ a low socio-economic level.

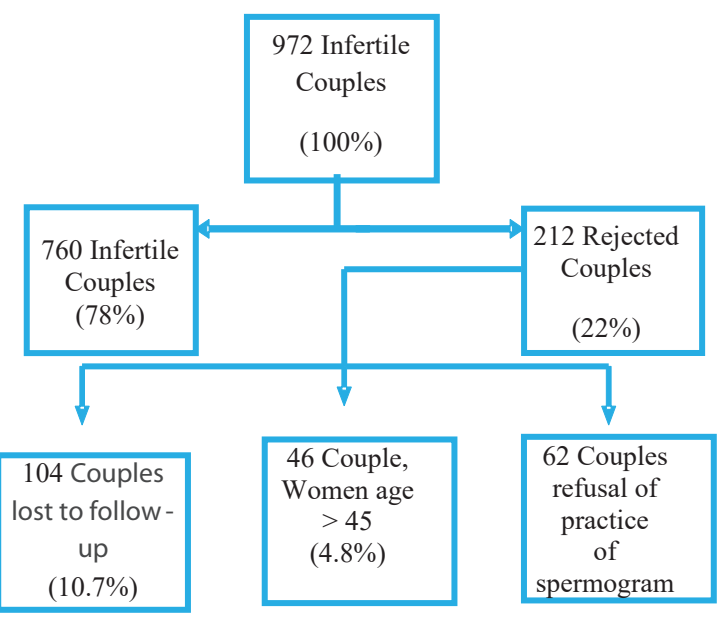

Figure 1: Causes of exclusion of infertile couples.

Table 1: General parameters.

\begin{tabular}{|c|c|c|}
\hline Infertility Factors & Percentage \% & Number \\
\hline \multicolumn{3}{|l|}{ Socio- économic level } \\
\hline High & 15 & 114 \\
\hline Average & 71 & 540 \\
\hline Low & 14 & 106 \\
\hline \multicolumn{3}{|l|}{ Type of infertility } \\
\hline Primary & 74 & 566 \\
\hline Secondary & 26 & 194 \\
\hline \multicolumn{3}{|c|}{ Duration of infertility (ans) } \\
\hline$\leq 2$ & 31,2 & 237 \\
\hline 3- 5 & 37,8 & 287 \\
\hline$\geq 5$ & 31 & 236 \\
\hline \multicolumn{3}{|l|}{ Woman's age } \\
\hline$\leq 30$ & 34.5 & 262 \\
\hline $31-35$ & 32 & 243 \\
\hline $36-40$ & 22.8 & 173 \\
\hline $41-45$ & 10.7 & 82 \\
\hline \multicolumn{3}{|l|}{ Age of man } \\
\hline$\leq 30$ & 8.8 & 66 \\
\hline $31-35$ & 23.3 & 177 \\
\hline $36-40$ & 28.6 & 217 \\
\hline $41-45$ & 18.8 & 143 \\
\hline$>45$ & 20.5 & 157 \\
\hline Total & 100 & 760 \\
\hline
\end{tabular}

Citation: Belhachemi N, Zelmat SA, Chafi B, Foughal M, Arabe WM (2020) Description of the characteristics influencing the therapeutic management of infertile couples in western Algeria. Glob J Fertil Res 5(1): 016-022. DOI: https://dx.doi.org/10.17352/gjfr.000017 
- $74 \%$ of the couples had primary infertility and $26 \%$ secondary infertility.

- The average duration of infertility was $4.8 \pm 0.2$ years (min 6 months, max 25 years) and the median was 4 years. $69 \%$ of the infertile couples had infertility for more than 2 years and $31 \%$ for more than 5 years.

- The average age of women was $33.2 \pm 0.4$ years ( $\min 18$, max 45), and the median was 33 years. The distribution by age group shows that $33.5 \%$ were over 35 years of age, of which $10.7 \%$ were over 40 years of age.

The average age of men was $39.5 \pm 0.5$ years (minimum was 23 , maximum 71 ) and the median was 39years. $68 \%$ of men were over 35 and $20.5 \%$ over 45 .

B. Origins of infertility and different male and female causes

The male origin of infertility was the most dominant at $30.4 \%$, mixed at $29.2 \%$ and female at $27 \%$. The unexplained origin was $13.4 \%$.

1- Male causes (Figure 2)

The spermogram came back normal in 41.5\%. Sperm count anomalies were dominated by severe OAT at $18.8 \%$, asthenospermia at $16 \%$ and moderate OAT at $15.7 \%$. Azoospermia was $4.2 \%$ and teratospermia $3.8 \%$.

2- Female causes (Table 2)

- The female origin of infertility was dominated by tubal causes at $23.4 \%$, ovulatory causes at $22.8 \%$.

- Of the $22.8 \%$ of ovulatory disorders, polycystic ovary syndrome (PCOS) was the leading cause of ovulatory disorders at $9 \%$, followed by early ovarian failure at $6 \%$ and luteal insufficiency at $2.5 \%$.

\section{Discussion}

\section{Causes of exclusion of couples}

Caring for infertile couples is difficult and demanding. Many couples who consult for infertility are abandoned for

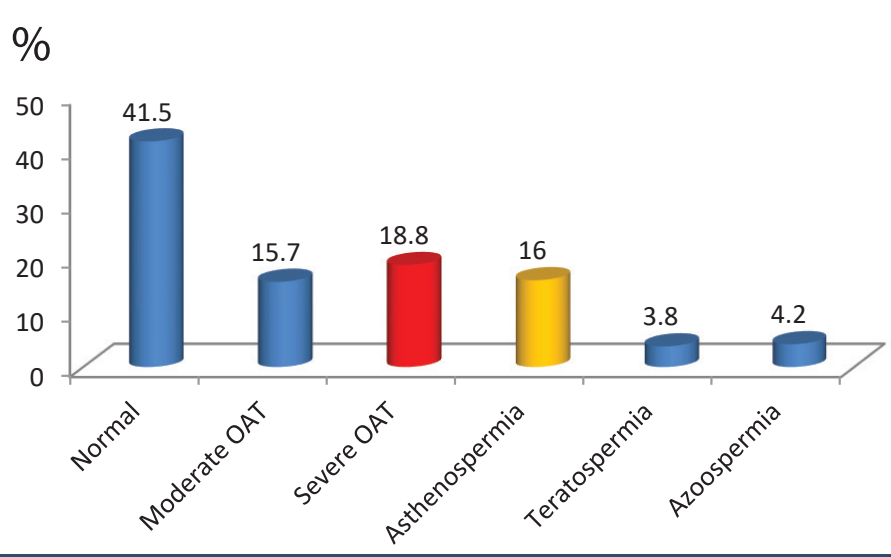

Figure 2: Male causes according to spermogram anomalies.
Table 2: The different female causes of infertility.

\begin{tabular}{|c|c|}
\hline Female causes & Percentage (\%) \\
\hline Présence & 56.2 \\
\hline - tubal & 23.4 \\
\hline - ovulatory & 22.8 \\
\hline - utérine & 3.9 \\
\hline - endométriosis & 3.5 \\
\hline - cervical abnomalities & 2.6 \\
\hline Absence & 43.8 \\
\hline Total & 100 \\
\hline
\end{tabular}

a variety of reasons. In our study, $22 \%$ of the couples were not included with $10.7 \%$ lost, $4.8 \%$ of the women were over 45 years old with a collapsed ovarian reserve and in $6.5 \%$ the man refused to have a spermogram and/or to be involved in the follow-up. Ferreira, et al. [21] in their 2007 study, out of 685 infertile couples who consulted the Reproductive Medicine department of Toulouse University Hospital for the first time, found a drop-out rate of $19.6 \%$ before treatment and $22.8 \%$ during treatment. Brandes, et al. in 2009 [22] showed that half of the couples who dropped out stopped before starting any treatment. Couple drop-out rates differ from one centre to another and the reasons for dropping out are: poor prognosis, spontaneous pregnancy, psychological suffering, adoption or separation of the couple.

\section{Characteristics influencing couple infertility}

\section{General factors}

- Type of infertility: Recent studies show a predominance of primary over secondary infertility: $74 \%$ in our study, $68 \%$ in the Walschaerts study [23] and for Safarinejad, [24] a significant increase in primary infertility from 2.6 to $5.5 \%$ from $1985-2000$. While other studies estimate that secondary infertility is the most prevalent form of infertility in the world $[25,26]$. secondary infertility is mainly related to post-abortion and postpartum infections [6]. These infertilities are described as "preventable" infertilities [27].

- Duration of infertility: In our study the average duration of infertility was 4.8 years $\pm 0.2,3$ years in Stan's study [28] and $2.8 \pm 2$ years in Walschaerts' study [23]. This seniority of infertility can be explained by taking several factors into account:

Medical factor: In the absence of a specialised centre, care for the infertile couple remains poor and the couple remains lost in the face of sometimes multiple and contradictory opinions. Whereas the infertile couple must be cared for in a specialised centre with a multidisciplinary team which makes it possible to establish a prognosis and guide the couple towards a codified course of action.

Social factor: The woman is the first person responsible for the infertility in the couple and she is the first to present herself for consultation. We sometimes note a resistance on 
the part of men in our society to have a spermogram because of the confusion in terms of virility and fertility. This is why in our study we continued to favour the post-coital test although it was abandoned by most of the authors. However, it remains reliable when it comes back positive.

If the man in the couple presented himself for the first time at an andrology consultation, it is the woman who has to follow up instead of her husband by taking the results of the spermogram or other paraclinical tests back to the andrologist. In fact, it has been found that $60 \%$ of andrological consultations are made up of women. They act as an intermediary between the andrologist and their husbands for the most motivated of them.

We have also noted that many men have sometimes repeated failures in sperm collection due to the fact that the conditions for collection are not completely fulfilled. Hence the interest in improving the conditions and creating specialised centres to freeze sperm for use in Medically Assisted Procreation (MAP).

Economic factor: It constitutes a prognostic factor in the care of the infertile couple. Several studies show that the cost of treatment is a very important factor in abandonment in some countries $[29,30]$.

Care for infertile couples in Algeria is free of charge in public hospitals. The estimate of the socio-economic level of the population studied found an average level in $71 \%$ and a low level in $14 \%$. This population could not afford examinations, hormone therapies that are $80 \%$ reimbursable by social security for the contributing population who remain beneficiaries, and LDC techniques, particularly IVF/ICSI, which are excessively expensive. In our study, it was noted that only $5.8 \%$ of infertile couples had used LDC techniques in their past, with $1.8 \%$ using IVF/ICSI, in private and sometimes foreign centres.

- The woman's age is probably the most important factor in any care for the infertile couple. All the studies show that as the age of women in the care centres is increasing, the results are likely to be poorer due to the decrease in natural fertility in women from the age of 35 onwards [31]. The age assessment of women in our population remains similar to other infertility consultant populations.

In our society and according to the National Multiple Indicator Survey 3 [32], the decrease in the age of marriage and consequently the age of first pregnancy contribute to an increase in the age of patients seeking medically assisted reproduction. The average age of marriage has risen to 29.8 years for women and 33.5 years for men, whereas ten years ago the average age of marriage was 18.3 and 23.8 years for women and men respectively. The age of first pregnancy is currently reported to be 31.02 years for women.

According to the FIVNAT [33] data, the age of patients entering the in vitro fertilisation (IVF) cycle has risen in 20 years from 33.3 years in 1986 to 34.5 years in 2004, and those aged 40 and over from $12 \%$ to $17 \%$. A Dutch team from Groningen [34] has shown, in a study of 10,436 women, that parallel to this increase in age at first pregnancy, there is a decrease in age at the first consultation in their infertility centre. The average age at the first consultation rose from 27.7 years in 1985 to 31.3 years in 2005. Moreover, the percentage of women over 35 years of age was $7.9 \%$ in 1985 , compared to $29.5 \%$ in 2005.

- Age of the man: similarly an increase in the age of men who consult for infertility has been noted. In his study Walschaerts. $M$ [20] reports that the average age of infertile men was $34 \pm 6$ years ( $62 \%$ had $\leq 35$ years); the average age of men was 34.3 in insemination (2204 IUI) and 34.8 in IVF (1286 IVF) for Bellvers [35]. Our study found a much older male population compared to these two studies (39 versus 34 years) with a percentage in the age distribution which represents the opposite of ours ( $62 \%$ for those 35 years and under versus $68 \%$ for those over 35 years).

\section{Origins and causes of infertility}

Our study reveals that male infertility accounts for $30.4 \%$, similar to other studies $[20,36]$. Other studies show a higher rate: more than 33\% in a Dutch study in 2002 and in another study published the same year [37,38], 39\% according to FIVNAT data [33]. The Donkers study [39] gives a lower figure of $25 \%$.

For Donckers [39], the etiologies listed are male factors (25\%), ovulatory disorders (17\%), tubal alterations (7\%) and unexplained infertility (10\%). Snick, et al. [20] report $30 \%$ unexplained infertility, 30\% male infertility including $4.5 \%$ azoospermia, $26 \%$ ovulatory disorders, $13 \%$ tubal alterations, $3.2 \%$ endometriosis and $28 \%$ cervical mucus alterations. A study by Maheshawani [40.] found $20 \%$ ovulatory problems, $19 \%$ tubal, $34.4 \%$ male and $22.4 \%$ unexplained. Disaggregating women over and under 35 years of age, he finds a much higher rate of unexplained in those over 35 years of age indicating hidden ovarian failure [40.]. Anovulation, fallopian tube disease, pelvic adhesions, endometriosis and unexplained infertility are the main female causes for Robert, et al. [41].

All these studies demonstrate the predominance of the male origin of infertility in different countries of the world in relation to a decrease in sperm quality and quantity. This deterioration in sperm concentration, which has been observed since the second half of the twentieth century [19] in western countries and probably in our own, is revealed by this percentage which is consistent with these studies. This alteration in sperm concentration is such that it could result in a decrease in the occurrence of pregnancy. In the study by Snick and Maheshawani $[20,40]$, the frequency of the different origins and causes of infertility was found to be more or less the same. Snick's study found an azoospermia rate identical to ours and raised an alteration of the cervical mucus in $28 \%$, which is an avenue of research on mucus-sperm histocompatibility [20].

However, the tubal causes in our population are much more important than the figures reported in these studies, in relation to the increase in salpingitis secondary to sexually transmitted infections. 
Given the high prevalence of Chlamydiae trachomatis infection in upper genital infections and the often symptomatic or even asymptomatic pauci character of this pathology linked to this germ, some recommendations have underlined the need for systematic screening for Chlamydiae trachomatis among young populations at risk. Other authors have also suggested that this screening should be extended to couples suffering from infertility [41].

\section{Conclusion}

Infertility is a problem encountered by an increasing number of couples.

Indeed, the analysis of the factors influencing infertility has shown that the primary type and significant duration of infertility, the advanced age of the woman and the man are pejorative elements in the care of couples because they make the chances of conception minimal even when MPA techniques are used the success rate is likely to be low.

The greater male origin of infertility than the female suggests a deterioration in sperm parameters probably related to environmental factors that are toxic to human fertility. The management of tubal infertility remains expensive and is the responsibility of LDC technologies, mainly IVF.

Information for couples on human reproduction is essential. Couples should be encouraged to marry at a younger age and to plan their desire for children as early as possible. In case of difficulty, they should be encouraged to consult earlier in specialised centres as the risk of infertility will be increased.

\section{Limitations of the study}

The search for the causes of infertility was limited to the basic infertility check-up. The therapy received by the couple was limited and depended on their socio-economic level.

\section{Acknowledgements}

I would like to thank the couples who participated and gave their consent to carry out this study. I would also like to thank all the staff of the unit and first and foremost the former head doctor Pr CHAFI. B who has the merit of having opened this unit within the public hospital, a first in Algeria.

\section{References}

1. Zegers-Hochshild F, Adamsan GD, de Mouzon J, Ishihara O, Mansour R, et al. (2009) International committee for monitoring assisted reproductive technology (ICMART) and WHO revised glossary of ART terminology. Fertil Steril 92: 1520-1524. Link: http://bit.ly/34iCiXQ

2. Cooper TG, Noonan E, von Eckardstein S, Auger J, Baker HW, et al. (2010) World health organization reference values for human semen characteristics. Hum Reprod 16: 231-245. Link: http://bit.ly/3r8W2HI

3. Lansac J, Guérif $F(2005)$ AMP: l'assistance médicale à la procréation en pratique. Elsevier Masson. 602. Link: https://bit.ly/2K6QFHG

4. Zegers-Hochschild F, Adamson GD, Dyer S, Racowsky C, de Mouzon J, et al (2017) The International Glossary on Infertility and Fertility Care. Fertil Steril 108: 393-406. Link: http://bit.ly/3qVnEQ1
5. World Health Organization (1999) WHO laboratory manual for the examination of human semen and sperm-cervical mucus interaction. Cambridge University Press 138

6. Inhorn MC, Patrizio P (2015) Infertility around the globe: new thinking on gender, reproductive technologies and global movements in the 21 st century. Hum Reprod 21: 411-426. Link: http://bit.ly/385Q557

7. Quatrième Congrès international du Gieraf sur la fertilité, Du bon usage de la procréation médicalement assistée, 6 Mars 2013. [Consulté le 20/07/2014]. Disponible à partir.

8. Bushnick T, Cook JL, Yuzpe AA, Tough S, Collins J (2012) Estimating the prevalence of infertility in Canada. Hum Reprod 27: 738-746. Link: http://bit.ly/3achrcx

9. Thonneau P, Marchand S, Tallec A, Ferial ML, Ducot B, et al. (1991) Incidence et causes principales de l'infertilité chez une population résidente(1.850.000) de trois régions françaises (1988-1989). Hum Reprod 6: 811-816. Link: http://bit.ly/385POPD

10. Annabi M (2008) L'infertilité au Maghreb, Aspect statistique. 3C Etudes. To see, or not to see: that is the question! Procréation médicalement assistée en Algérie. Bulletin.

11. Linsten AM, Eijkemans MJ, Hunault CC, Bouwmans CA, Hakkaart L, et al. (2007) Predicting ongoing pregnancy chances after IVF and ICSI a national prospective study. Hum Reprod 22: 2455-2462. Link: http://bit.ly/3aftAgB

12. Belhachemi N, Hakim F, Chenni K (2018) Étude des facteurs pronostiques de survenue de grossesse chez les couples infertiles pris en charge en dehors de la fécondation in vitro / injection intra-cytoplasmique de spermatozoide dans l'Ouest Algérien. 293-302.

13. Gnoth C, Godehardt E, FrankHerrmann P, Friol K, Tigges J, et al. (2005) Definition and prevalence of subfertility and infertility. Hum Reprod 20: 11441147. Link: http://bit.ly/2WimEr9

14. Thonneau $P$ (2000) Les paternités tardives. CNGOF. Extrait des Mises à jour en Gynécologie Médicale, Andrologie.

15. Bushnick T, Coock J, Hughes E (2012) Le recours aux services médicaux d'aides à la conception. Statistiques Canada.

16. Boivin J, Bunting L, Collins JA, Nygren KG (2007) International estimates of infertility prevalence and treatment-seeking: potential need and demand for infertility medical care. Hum Reprod 22: 1506-1512. Link: http://bit.ly/2WgA9Ya

17. Agarwal A, Mulgund A, Hamada A, Chyatte MR (2015) A unique view on male infertility around the globe. Reprod Biol Endocrinol 13: 37. Link: http://bit.ly/3ahpGnp

18. Carlsen E, Giwercman A, Keiding N, et al. (1992) Evidence for decreasing quality of semen during past 50 years. BMJ 305: 609-613. Link: http://bit.ly/3gT7DVT

19. Snick K, Snick TS, Evers JL, Collins JA (1997) The spontaneous pregnancy prognosis in untreated subfertile couples: the walcheren primary care study. Hum Reprod 12: 1582-1588. Link: http://bit.ly/3muwlbe

20. Teillet Sanchez E, Ferreira M (2014) Suivi des couples 5 ans après leur première consultation pour infertilité. Thèse Pour le diplôme d'état de docteur en médecine spécialisée tou3 1522/15 clinique université Toulouse iii - Paul Sabatier Facultés de médecine. Link: http://bit.ly/3gSv0Pu

21. Brandes. M, van der Steen JO, Bokdam SB (2009) Quand et pourquoi les couples infertiles ne cessent leurs soins de fertilité? Une étude de cohorte longitudinale dans une population soins de hypofertilité secondaire. Hum Reprod 24: 3127-3335.

22. Walschaerts M (2011) La sante reproductive de l'homme : méthodologie et statistique. Thèse doctorat. Biostatistique - épidémiologie. Université de Toulouse. Link: http://bit.ly/3p11vxX 
23. Safarinejad MR (2008) L'infertilité chez les couples dans une étude basée sur la population en Iran: la prévalence et les facteurs de risque associés. Int $\mathrm{J}$ Androl 31: 303-314.

24. Nachtigall RD (2006) International disparities in access to infertility services Fertil Steril 85: 871-875. Link: http://bit.ly/38ewtMm

25. ORC Macro, The World Health Organization (2004) Infecundity, infertility, and childlessness in developing countries. DHS Comparative Reports No. 9. World Health Organization, Geneva, Switzerland. Link: http://bit.ly/3nn22K0

26. Okonofua F (1999) Infertility and Women's Reproductive Health in Africa / Infertilité et Santé Reproductive des Femmes en Afrique. African Journal of Reproductive Health 3: 7-12. Link: http://bit.ly/38afOJA

27. Stan C, Prêtre M, Boulvain M, Campana A (1999) Aspects diagnostiques et pronostiques de la stérilité à l'hôpital de Sierre. Schweiz Med Wochenschr 129: 1321-1327. Link: http://bit.ly/3oXEpZ2

28. Teillet Sanchez, Ferreira M (2014) Suivi des couples 5 ans après leur première consultation pour infertilité. Thèse Pour le diplôme d'état de docteur en médecine spécialisée tou3 1522/15 clinique université Toulouse iii - Paul Sabatier Facultés de médecine. Link: http://bit.ly/3oW3wLD

29. Khalili MA, Kahraman S, Ugur MG, Agha-Rahimi A, Tabibnejad N (2012) Suivi des patients infertiles après des cycles d'ART forfait: un rapport préliminaire de l'Iran et de la Turquie. Eur J Obstet Gynecol Reprod Biol 161: 38-41.

30. Nelson SM, Anderson RA, Broekmans FJ, Raine-Fenning N, Fleming R, et al. (2012) Anti-Müllerian hormone: clairvoyance or crystal clear? Hum Reproduct 27: 631-636. Link: http://bit.ly/2IRat18

31. Enquête nationale à indicateurs multiples. (MICS). Algérie 2006.

32. Bellaisch-Allart J, Devaut A, Ayel J, de Mouzon J (2004) La femme de 40 ans et plus en FIV et en ICSI. Données FIVNAT. Gyn Obstetrique 32: 730-736. Link: http://bit.ly/3oXcA2V
33. Dupas C, Christin S (2008) Quels sont les facteurs qui modifient la fertilité en 2008 ? Maitre Annale d’Endocrinologie 69: S57-S61. Link: http://bit.ly/3mniGI8

34. Bellver J, Garrido N, Remohí J, Pellicer A, Meseguer M (2008) Influence of paternel âge on assisted reproduction outcome. Reprod Biomed 5: 595-604. Link: http://bit.ly/3mn5iE1

35. Gunby J, Bissonnette F, Libroch C, Cowan L (2009) Assisted reproductive technologies in Canada: 2005 results from the Canadian Assisted Reproductive Technologies Register. Fertile steril 91: 1721-1730. Link: http://bit.ly/3guPfwa

36. Stolwijk M, Wetzels AM, Braat DD (2000) La probabilité cumulative d'atteindre une grossesse en cours après la fécondation in vitro et l'injection intracytoplasmique de spermatozoïdes selon l'âge de la femme, le diagnostic de la sous-fécondité et hypofertilité primaire ou secondaire. Hum Reprod 15 : 203-209.

37. Olivius K, Friden B, Lundin K, Bergh C (2002) Cumulative probability of live birth after three in vitro fertilization/intracytoplasmic sperm injection cycles. Fertil Steril 77: 505-510. Link: http://bit.ly/37nj9WF

38. Donckers J, Evers JLH, Land JA (2011) The long-term outcome of 946 consecutive couples visiting a fertility clinic in 2001-2003. Fertil Steril 96: 160164. Link: http://bit.ly/34fbNIS

39. Maheshwari A, Bhattacharya S, Johnson NP (2008) Predicting fertility. Hum Fertil 11: 109-117. Link: http://bit.ly/3gT5vNT

40. Barbieri RL, Strauss JF (2019) Female Infertility. Yen and Jaffe's Reproductive Endocrinology (Eighth Edition). Physiology, Pathophysiology Clinical Management 556-581.e7. Link: http://bit.ly/2Whnzlj

41. Samra Z, Soffer Y, Pansky M (1994) Prevalence of genital Chlamydia and mycoplasma infection in couples attending a male infertility clinic. Eur $\mathrm{J}$ Epidemiol 10: 69-73. Link: http://bit.ly/38nET47
Discover a bigger Impact and Visibility of your article publication with

Peertechz Publications

Copyright: (c) 2020 Belhachemi N, et al. This is an open-access article distributed under the terms of the Creative Commons Attribution License, which permits unrestricted use, distribution, and reproduction in any medium, provided the original author and source are credited. 